\title{
Factors Associated With Obstetric Fistula Among Reproductive Age Women in Ethiopia, Community Based, Case Control Study
}

ATAKLTI Weldegebriel Gebertsadik ( $\nabla$ atakltigebertsadik@gmail.com )

Tigray Health Research Institute, Mekelle, Tigray, Ethiopia

\section{Gebremedhin Gebreegziabiher Gebrehiwot}

Tigray health reserch institute

\section{Abraham Aregay Desta}

Tigray health reserch instiute

\section{Kiros Fenta Ajemu}

Tigray health reserch instiute

\section{Asfawosen Aregay Berhe}

Tigray health reserch institute

\section{Tewolde Wubayehu Woldearegay}

Tigray health reserch instiute

\section{Kiros Demoz Ghebremedhin}

Tigray health reserch instute

\section{Nega Mamo Bezabih}

Tigray health reserch institute

\section{Research}

Keywords: Obstetric fistula, maternal morbidity, Ethiopia

Posted Date: August 25th, 2020

DOI: https://doi.org/10.21203/rs.3.rs-61513/v1

License: () This work is licensed under a Creative Commons Attribution 4.0 International License. Read Full License 


\section{Abstract}

Background: Obstetric fistula is major public and reproductive health concerns in Ethiopia .It are most disturbing among all maternal morbidities.

Method: A community-based unmatched case control study was conducted from the EDHS, 2016 dataset. All 70 cases and 210 non cases were selected using random number table from the dataset. Reproductive age mothers who had experiencing lifelong obstetric fistula were considered as cases .Logistic regression was used to identify factors associated with obstetric fistula at $95 \%$ confidence interval. Factors significant at $p$ value of $\leq 0.05$ were included into multivariable logistic regression model to generate adjusted odds ratios.

Results: The majority of fistula cases were from rural residences. Independent risk factors associated with obstetric fistula included age at first marriage, rural residence, poorest wealth index and decision making for contraceptive use mainly husband partner.

\section{Conclusion}

Obstetric fistula is a major public and reproductive health concern in Ethiopia. Majority of women with obstetric fistula were from rural areas. Comprehensive intervention strategies should be in place customized to different government hierarchies (national, regional and district level) including household and individual level interventions for combating obstetric fistula by giving an emphasis on the identified risks.

\section{Plain English Summary}

Globally, each year between 2-3 million women are affected by obstetric fistula. It is common in developing nations, mainly in sub-Saharan Africa and Southeast Asia where suitable and timely care and treatment are hard to find for this case. This devastating condition adversely affects women's physical and mental health. There is little research concerning the experiences of women living with leakage of urine and/or feces in Ethiopia .Therefore, this article provides a better understanding of identifying factors associated experienced a constant leakage of urine or stool from the vagina.

We collected data from the women reproductive age group from the Ethiopia demographic health survey and the factors associated with the disease. Our findings show that, obstetric fistula was a significantly high rural residence, poorest wealth index, age at first marriage less than 18 years , and decision making for contraceptive use mainly husband partner. Comprehensive intervention strategies should be in place customized to different government hierarchies for combating the adverse condition.

\section{Background}

Obstetric fistula is an atypical link between the vagina, rectum , and/or bladder that may arise after protracted and obstructed labor. Among all maternal morbidities, obstetric fistula is one of the most disturbing for the maternal health. Childbirth encounters momentous risks for women and new born. (1).Globally, each year between 50000 to 100000 women are pretentious by obstetric fistula (2).

These risks reflect global inequity: Obstetric fistula (OF) is a situation that residue prevalent in developing nations, mainly in sub-Saharan Africa and Southeast Asia where suitable and timely obstetrical care is hard to find or scarce. It is anticipated that more than two million young women survive with untreated obstetric fistula in Asia and sub-Saharan Africa (3).

Ethiopia's fertility rate is among the uppermost countries in the world and only $50 \%$ of births attend by a skilled birth attendant. Besides, rural areas where $80 \%$ of the population resides, poor and under-nourished women countenance 
superior risk and challenges to obstetric fistula reduction (4).

Women victumed by obstetric fistula are often deserted by their husbands, stigmatized by the community. Hence, leads to low self-esteem, depression and long lasting emotional trauma (5).According the USAID report, it is estimated that nine thousand women in Ethiopia develop obstetric fistula every year, and that up to hundred thousand women are living with untreated fistula (6).

Information from different literature indicated that obstetric fistula linked to social-economic and cultural factors including poverty, illiteracy, accessibility of health facilities, duration of labour, respondent height, young age at marriage, place of residence with lack of emergence obstetric care (7-11).

Community-based surveys generally provide wider coverage, better representation of national population and more opportunities to collect a wide range of data. Due to nationally representative samples and use of similar questions across surveys, the EDHS surveys provide a unique set of data to asses factors associated with obstetric fistula. Identifing factors associated with obstetric fistula using various study design is mandatory.

To our knowledge, no nationally representative community based study with case control study design has documented to identify risk factors for obstetric fistula in Ethiopia. The aim of this study was therefore to identify the risk factors for obstetric fistula from a local context among women in Ethiopia.

\section{Methods}

\section{Data source and sampling techniques}

The study participants chosen using a stratified, two stage cluster design, and enumeration areas were the sampling units for the first stage. In the first stage, 645 enumeration areas were randomly selected: 202 in urban areas and 443 in rural areas. In the second stage, a fixed number of 28 households per cluster were selected randomly for each enumeration areas. The 18,060 households were randomly selected and 16,650 households were eligible and interviewed. Additional information about the methodology of EDHS 2016 can be accessed in the published report of the main findings of the survey [12].

Every selected reproductive age women was included and data were collected on various socioeconomic, obstetric and nutrition variables. As our focus in this study was 15-49 years aged women, we extracted the EDHS 2016 data set. We found in the data set 70 women with experienced obstetric fistula (Cases) and 210 (Controls) selected from the data set using random number table and 280 women were included in the final analysis showed sampling techniques (Figure :1).

\section{Sample design}

A community-based unmatched case-control study was conducted among reproductive age women.

\section{Variables and measurements:}

\section{Dependent variable:}

The outcome variable was fistula, which is defined as reproductive aged women experiencing lifelong obstetric fistula.

\section{Independent variables:}

The selection of the independent variables was guided by the literature and availability of the variables in the data set. Some of the independent variables for obstetric fistula among reproductive age women 15-49 years. 
Maternal characteristics: maternal age, maternal educational status, maternal antenatal care follow up, whether the mother is currently living with her husband or not, whether the mother is engaged in income generating work or not.

Household characteristics: number of household members, residence, wealth index ranked in to five (poorest, poorer, middle, richer and richest) , sex of household head.

Obstetric characteristics: Place of delivery, ANC follow up, size of child at birth, postnatal check up, Preceding birth interval, Height $(\mathrm{Cm})$ and ever had a terminated pregnancy.

\section{Anthropometric measurements:}

The nutritional category of women was measured by use of height and body mass index (BMI). To calculate BMI, during EDHS measured the height and weight of women age 15-49 years. BMI is used to measure thinness or obesity. BMI is defined as weight in kilograms divided by height in meters squared $(\mathrm{kg} / \mathrm{m} 2)$. A BMl below $18.5 \mathrm{~kg} / \mathrm{m} 2$ shows thinness. A BMI below $12-17 \mathrm{~kg} / \mathrm{m} 2$ indicates severe undernutrition BMI of $25.0 \mathrm{~kg} / \mathrm{m} 2$ or above shows overweight or obesity. Height was also categorized in a single cut off point $<145 \mathrm{~cm}$ as short stature.

\section{Wealth index}

A wealth index in the EDHS survey was measure based on household asset data to classify individuals into 5 wealth indeces (poorest, poorer, medium, richer and richest). Variables incorporated in the wealth index were ownership of chosen household assets (television, bicycle or car), size of agricultural land, number of livestock and materials used for house construction [13].

\section{Data Analysis}

EDHS have developed recode files in order to facilitate data analysis. All data tartan for its completeness and reliability. Preliminary analysis was done to check the first round finding. In all analysis, sample weights have done due to two stage cluster sampling design in the EDHS data set to adjust for the imbalance probability selection among the strata [12]. All the analyses were performed using STATA version 14.0 Categorical type of data was analyzed by descriptive statistics (frequency and percentage).

Logistic regression analysis was used to identify factors associated with obstetric fistula. Bivariate analysis was carried out to see the crude association of each independent variable with the outcome variable (Obstetric fistula). Those independent variable variables with $P$-value $\leq 0.05$ in the bivariate analysis were included in the final multivariable logistic regression analysis to adjust for confounding and to identify the final factors associated with obstetric fistula. Logistic regression method was used during the multivariable logistic regression analysis. Before inclusion of predictors to the final logistic regression model, the multi-collinearity was checked using $\mathrm{VIF}<10 /$ Tolerance $>0.1$ for continuous independent variables. The goodness of fit of the final logistic model was tested using Hosmer and lemeshow test at $p$ value of $>0.05$. The strength of association of the predictors and outcome variable have been indicated by Adjusted odds ratio at $95 \%$ confidence interval. The significant association was declared at $p \leq 0.05$ for the final logistic regression model

\section{Ethical Considerations:}

The study proposal got ethical approval from Tigray health research institute and formal letter of permission was obtained from measure DHS project website to access the dataset (http://www.measuredhs.com).

\section{Results}

\section{Socio-demographic and other characteristics for cases and controls of the mothers}


From a total of 280 samples size, (70 cases and 210 controls) were included in the final analysis. Majority of the case were aged $34-49$ (44\%) while controls were aged $15-23$ years $37.1 \%$. More than half $57.1 \%$ of mothers in cases and $42.4 \%$ controls have no education attainment. Majority of cases $84.3 \%$ and $64.8 \%$ controls were living in rural residence.

Regarding, wealth index poorest $30 \%$ of mothers in cases and $24.3 \%$ in controls. Majority of number of house hold members have equal or greater than four $62.1 \%$ of cases and $63.3 \%$.non controls. The majority of mothers in cases and control group (68.6\% and $58.6 \%$ respectively) were married. More than half numbers $52.9 \%$ of mothers in cases and $43.3 \%$ in controls were Orthodox believers .One third number of mothers $38.6 \%$ in cases and $46.7 \%$ in non controls had work (Table:1).

\section{Obstetrics characteristics of cases and controls}

More than half $58.6 \%$ in cases and $62.9 \%$ in controls place of delivery in home. One from four mothers $27.6 \%$ in cases and $24.7 \%$ in controls were not following Antenatal care.Size of baby very larger $18 \%$ and larger than average $16 \%$ in cases and $21.6 \%$ and $18.9 \%$ in controls respectively. Majority of mothers $96.6 \%$ in cases and 86.6 in controls were not follow postnatal check up. Greater than One fourth number of mothers $31.3 \%$ in cases and $23.6 \%$ in controls were less than 24 months birth interval. Almost majority of the cases $85.7 \%$ and $88.1 \%$ in controls were taller than $150 \mathrm{~cm}$. Majority of mothers in cases $80 \%$ and $90.5 \%$ in controls not ever had a terminated pregnancy (Table:2).

\section{Factors Associated with obstetric fistula among mothers aged 15- 49 years:}

In bivariate logistic regression analysis age at first marriage, Height, wealth index place of residence, has television, literacy, number of house hold members, ever had a terminated and decision maker for using contraceptive pregnancy significant associated with obstetric fistula. In multivariable logistic regression analysis age at first marriage, wealth index poorest, rural residence and decision maker for using contraceptive mainly husband, partner significant associated with obstetric fistula.

In multivariable analysis age at first marriage less than 18 years were 3.3 times ( $\mathrm{AOR}=3.39 ; 95 \% \mathrm{Cl}: 2.832,4.601)$ more likely with developing fistula than greater than 18 years aged. Wealth index poorest category 4.6 times $(A O R=4.62 ; 95 \%$ $\mathrm{Cl}: 2,238,5.015)$ more likely with developing f fistula than richest wealth index. Rural residences 5.14 times $(A O R=4.62$; $95 \% \mathrm{Cl}: 4.262,7.521)$ more likely with developing fistula than urban residence. Decision making for contraceptive use mainly husband, partner 1.3 times $(A O R=4.62 ; 95 \% \mathrm{Cl}: 1.124,1.670)$ more likely with developing fistula than joint decision (Table 3).

\section{Discussion}

The main goal of this unmatched case control study was to identify factors associated with obstetrics fistula in Ethiopia. Despite, substantial efforts by the Ethiopia government and non-governmental organizations to raise health facilities, improve quality of services, and increase access to care, inequalities in maternal healthcare obstetric fistula is still the main concern in Ethiopia.

Our analysis identified age at first marriage, rural residence, poorest wealth index and decision making to use contraceptive husband only risk factors for developing obstetrics fistula. Age at first marriage less than 18 years were 3.3 times $(\mathrm{AOR}=3.39 ; 95 \% \mathrm{Cl}: 2.832,4.601)$ more likely with developing fistula than greater than 18 years aged. This finding also corresponds to studies in developing countries, in Tigray, Ethiopia (7), in Sub-Saharan Africa (14) and Uganda Demographic and Health Survey (15).

The possible reason might be due to before the pelvic girdle is fully developed in young adolescent may explain the elevated risk of distress from obstetric fistula women bearing children apparently. Besides, when labor happen in 
situations not equipped to deal with dystocia.

Rural residence more likely with developing fistula than urban residence in line with study in Eretria (16) and Democratic Republic of the Congo (17). This might be in the rural residence

shortage of antenatal care, extended labor and deprived health seeking behavior such as delay in accessing emergency care due to intriguing more than one move from home to reach the delivery place and no lack of decision making in emergency by family members were associated with the occurrence of obstetric fistula. Besides, in rural areas associated with lower geographical ease of access to health facilities. Besides economic troubles, there are also socio-cultural issues related to lower male involvement and support for women's health care access. Wealth index poorest category more likely with developing fistula than richest wealth index.This result is in agreement with the study in South-eastern rural community of India (18), Tanzania (19), Uganda: demographic and health survey data (20) and Nairobi, Kenya (21). The possible reasons might be that women who had a better wealth index may assist them easily reach to the health facilities for their paramount health outcomes. Besides, a better wealth index may lessen the difficulty of obtaining resource to easily reach health care. As a result, women, who could not have enough money to pay for these expenses found it complicated or even impossible to visit health facilities.

Decision making for contraceptive use mainly by husband, partner 1 more likely with developing fistula than Joint decision .This finding is concurrent with in sub-Saharan Africa (22) and North Western, Nigeria (21).The possible reason might be the women for non-use of modern contraceptive methods was husband antagonism, desire for additional children, religious ban. This is not amazing as culture and religion has positioned men as the top of the family and women can not make decisions in relation to their own health.

The desire for more children given by some of the women is not surprising as the majority of the women with obstetric fistula delivered a stillbirth. These study findings present the evidence for the need of male participation in contraception and other reproductive health issues like the prevention of obstetric fistula were men play an important role.

In spite of the limitations of our study, this is community based case-control study to identify

factors associated with obstetric fistula development and it is the only national representative and community base case control study taking place in Ethiopia. These findings can assist and identify women who are at increased risk for developing an Obstetric fistula and educate them about the risks of becoming pregnant before their bodies have matured and to identify the signs and symptoms associated with obstructed labor and emergency delivery.

Besides, the detection of at risk individuals may also help identify those who have developed obstetric fistula and help them seek care more quickly to reduce morbidity in the population. Resources aimed at helping child-bearing women can also be oriented to reduce risk factors in target populations and increase protective factors to lower obstetric fistula rates. We hope that the findings of this study will bring much needed attention to this serious condition and provide information to help those who are most likely to develop an obstetric fistula. Further longutidail study needed.

\section{Strengths And Limitations Of The Study}

The strength of this study was; it used national representative data which permit to generalize the results. It also functional all the DHS data principles like weighting. The limitation of this study was its cross-sectional design, cannot examine causation of the precedence in time between exposure and outcome. There were some missing values for some variables in the dataset .Being; the cases for obstetric fistula were lifelong. Therefore, the authors might be fail to consider some factors which could affect the interpretation of the results and the retrospective nature of the data and maternal verbal reports, recall bias might have been introduced. 


\section{Conclusions}

Obstetric fistula is a major public and reproductive health concern in Ethiopia. Majority of women with obstetric fistula were from rural areas. This analysis provides evidence that experience of obstetric fistula significant associated with age at first marriage, rural residence, poorest wealth index and decision making by husband alone. Comprehensive intervention strategies should be in place customized to different government hierarchies (national, regional, district level, house hold and individual level) including interventions for combating obstetric by giving stress on the identified risk factors. We advise health authorities at different hierarchies to design different intervention activities like to educating the community to avoid the risk of obstetric fistula due to pregnancy and delivery, strengthening family planning, antenatal care services and increased access to emergency obstetric care should be addressed extensively.

\section{Abbreviations}

ANC-Antenatal care, BMI-Body mass index, DHS-Demographic health survey, EDHS-Ethiopia demographic health survey, OF- Obstetric fistula, VIF-variance inflation factor, SAID- United States Agency for International Development.

\section{Declarations}

\section{Acknowledgements:}

Not applicable.

\section{Funding:}

Not applicable.

\section{Availability of data and materials}

All data supporting our findings will be shared upon request.

\section{Authors' contributions:}

A.G contributed to the concept, data extraction tool, conducted data extraction, analysis and interpretation of data, and wrote the first draft of the manuscript and revised it.GG, AA2,AA3,KD and TW contributed to the concept and participated in protocol development and KF reviewed assessment tool, reviewed analysis findings, and revised the draft and final manuscript. All authors read and approved the final manuscript.

\section{Competing interests:}

The authors declare that they have no competing interests.

\section{Consent for publication:}

Not applicable.

\section{Ethics approval and consent to participate}

Not applicable.

\section{References}


1. Bulletin of the World Health Organization2015; 93:60-62.

doi: http://dx.doi.org/10.2471/BLT.14.141473.https://www.who.int/bulletin/volumes/93/1/14-141473.pdf?ua=1

2. World health organization (WHO).Obstetricfistula.2018.https://www.who.int/news-room/facts-in-pictures/detail/10facts-on-obstetric-fistula

3. 10 facts on obstetric fistula [Internet]. Geneva: World Health Organization; 2014. Available from: http://www.who.int/features/factfiles/obstetric_fistula/en/ [cited 2014 Nov 28].

4. Mini Demographic and Health Survey, 2019. Addis Ababa: Ethiopian Central Statistical Agency

5. Tesfaye G. (2013). Survival Analysis of Time to Recovery from Obstetric Fistula at Yirgalem Hamlin Fistula Hospital, SNNPR, Ethiopia. MSc Thesis, School of Mathematical and Statistical Science, Hawassa University, Ethiopia. https://www.hilarispublisher.com/open-access/survival-analysis-of-time-to-recovery-from-obstetric-fistula-a-casestudy-at-yirgalem-hamlin-fistula-hospital-ethiopia-2155-6180-1000242.pdf

6. USAID situation assessment .Joint AusAID and USAID Review of Support to Hamlin Fistula Ethiopia (Ethiopia). 2013 https://reliefweb.int/sites/reliefweb.int/files/resources/joint-aus-us-gov-review-hamlin-fistula-ethiopia-final-report.pdf

7. Roka et al. Factors associated with obstetric fistulae occurrence among patients attending selectedhospitals in Kenya, 2010: a case control stu .BMC Pregnancy and Childbirth 2013, 13:56

8. L. Lewis Wall \& Shewaye Belay \& Tesfahun Haregot \& Jonathan Dukes \& Eyoel Berhan \& Melaku Abreha. A casecontrol study of the risk factors for obstetric fistula in Tigray, Ethiopia. Int Urogynecol J,2017, DOI 10.1007/s00192017-3368-6

9. Andargie AA, Debu A. Determinants of obstetric Fistula in Ethiopia. Afri Health Sci. 2017;17(3): 671-680. https://dx.doi. org/10.4314/ahs.v17i3.9

10. .L. Mubikayi et al. A Case-Control Study of Obstetric Fistula Risk Factors in the Democratic Republic of the Congo. Open Journal of Obstetrics and Gynecology, 6, 740-753.http://dx.doi.org/10.4236/ojog.2016.612092

11. Bashah et al. Consequences of obstetric fistula in sub Sahara African countries, from patients' perspective: a systematic review of qualitative studies. BMC Women's Health (2018) 18:106

12. Ethiopia Demographic and Health Survey, 2016. Addis Ababa: Ethiopian Central Statistical Agency.

13. Rahman et al. Wealth inequality and utilization of reproductive health services in the Republic of Vanuatu: insights from the multiple indicator cluster survey, 2007.International Journal for Equity in Health 2011, 10:58

14. Maheu-Giroux et al. Risk factors for vaginal fistula symptoms in Sub-Saharan Africa: a pooled analysis of national household survey data .BMC Pregnancy and Childbirth (2016) 16:82.

15. Marguerite L. Sagna, Nazrul Hoque,Thankam Sunil. Are some women more at risk of obstetric fistula in Uganda? Evidence from the Uganda Demographic and Health Survey. Journal of Public Health in Africa $2011 ; 2:(26) \mathbf{J}$

16. Samsom M Giliu et al. Factors Associated With Obstetric Fistula Among Women Admitted To Mendefera National Fistula Center, Eritrea. International Journal of Recent Scientific Research,2018:9(3ealth in Africa 2011 ; volume 2:e26

17. Mubikayi, L., Chow, E.J., Matson, D.O., Nzau, E. and Tandu, B. (2016) A Case-Control Study of Obstetric Fistula Risk Factors in the Democratic Republic of the Congo. Open Journal of Obstetrics and Gynecology,2016: 6(740-753).

18. Swain et al. Prevalence and risk factors of obstetric fistula: implementation of a need-based preventive action plan in a South-eastern rural community of India .BMC Women's Health (2020) 20:40

19. Bintabara, D., K. Nakamura, and K. Seino, Improving access to healthcare for women in Tanzania by addressing socioeconomic determinants and health insurance: a population-based cross-sectional survey. BMJ open, 2018. 8(9): p. e023013.

20. Rutaremwa Gideon . Factors Associated with Adolescent Pregnancy and Fertility in Uganda: Analysis of the 2011 Demographic and Health Survey Data.American Journal of Sociological Research 2013, 3(2): 30-35 
21. Jean-Christophe et .al .What does Access to Maternal Care Mean Among the Urban Poor? Factors Associated with Use of Appropriate Maternal Health Services in the Slum Settlements of Nairobi, Kenya. Matern Child Health J (2009) 13:130-137

22. Yaya et al. Women empowerment as an enabling factor of contraceptive use in sub-Saharan Africa: a multilevel analysis of cross sectional surveys of 32 countries .Reproductive Health (2018) 15:214

23. Nasir et al. Modern Contraceptives Utilization And Barriers Among Women With Obstetric Fistula In North Western Nigeria. ejpmr, 2017,5(02), 28-31

\section{Tables}

Table 1 Socio-demographic and other characteristics for cases and controls of the mothers, EDHS, 2016 


\begin{tabular}{|c|c|c|c|}
\hline \multirow[t]{2}{*}{ Variables } & \multirow[t]{2}{*}{ category } & Cases $(n=70)$ & Controls $(n=210)$ \\
\hline & & Freq $(\%)$ & Freq $(\%)$ \\
\hline \multirow[t]{3}{*}{ Maternal current age (years) } & $15-23$ & $16(22.9)$ & $78(37.1)$ \\
\hline & $24-33$ & $23(32.9)$ & 67(31.9) \\
\hline & $34-49$ & $31(44.3)$ & 65(31) \\
\hline \multirow[t]{4}{*}{ Maternal educational status } & No education & $40(57.1)$ & $89(42.4)$ \\
\hline & Primary & $22(31.4)$ & $74(35.2)$ \\
\hline & Secondary & $6(8.6)$ & $32(15.2)$ \\
\hline & Higher & $2(2.9)$ & $15(7.1)$ \\
\hline \multirow[t]{2}{*}{ Residence } & Urban & 11(15.7) & $74(35.2)$ \\
\hline & Rural & $59(84.3)$ & $136(64.8)$ \\
\hline \multicolumn{4}{|l|}{ Wealth index } \\
\hline & Poorest & $21(30.0)$ & $51(24.3)$ \\
\hline & Poorer & $10(14.3)$ & $26(12.4)$ \\
\hline & Middle & $14(20.0)$ & $26(12.4)$ \\
\hline & Richer & $10(14.3)$ & $27(12.9)$ \\
\hline & Richest & $15(21.4)$ & $80(38.1)$ \\
\hline \multicolumn{4}{|c|}{ Number of house hold members } \\
\hline & 1 & $36(12.9)$ & 29(13.8) \\
\hline & $2-4$ & $70(25.0)$ & $48(22.9)$ \\
\hline & $>4$ & $174(62.1)$ & 133(63.3) \\
\hline \multicolumn{4}{|l|}{ Maternal occupation } \\
\hline & No & $27(38.6)$ & $98(46.7)$ \\
\hline & Yes & $43(61.4)$ & 112(53.3) \\
\hline \multicolumn{4}{|l|}{ Marital status } \\
\hline & Never in union & $6(8.6)$ & $56(26.7)$ \\
\hline & Married & $48(68.6)$ & $123(58.6)$ \\
\hline & Living with partner & $2(2.9)$ & $4(1.9)$ \\
\hline & Widowed & $4(5.7)$ & $9(4.3)$ \\
\hline & Divorced & $8(11.4)$ & $13(6.2)$ \\
\hline & No longer living together/separated & $2(2.9)$ & $5(2.4)$ \\
\hline \multicolumn{4}{|l|}{ Religion } \\
\hline & Orthodox & $37(52.9)$ & $91(43.3)$ \\
\hline & Catholic & $0(0 \%)$ & $1(0.5)$ \\
\hline
\end{tabular}

Page 10/15 


\begin{tabular}{|lll|}
\hline Protestant & $7(10.0)$ & $49(23.3)$ \\
\hline Muslin & $26(37.1)$ & $68(32.4)$ \\
\hline Other & $0(0)$ & $1(0.5)$ \\
\hline
\end{tabular}

Table 2: Obstetrics characteristics of cases and controls of the mothers, EDHS, 2016( $n=280)$

\begin{tabular}{|c|c|c|c|}
\hline \multirow[t]{2}{*}{ Variables } & \multirow[t]{2}{*}{ Category } & Cases $(n=70)$ & Controls $(n=210)$ \\
\hline & & Freq $(\%)$ & Freq $(\%)$ \\
\hline \multirow[t]{2}{*}{ Place of delivery } & Home & $17(58.6)$ & $61(62.9)$ \\
\hline & Health facilities & $12(41.4)$ & $36(37.1)$ \\
\hline \multirow[t]{4}{*}{ ANC follow up } & No ANC visit & $8(27.6)$ & $24(24.7)$ \\
\hline & One & $1(3.4)$ & $8(8.2)$ \\
\hline & Two & $1(3.4)$ & $8(8.2)$ \\
\hline & Equal or greater Three & $19(65.5)$ & $57(58.8)$ \\
\hline \multicolumn{4}{|c|}{ Size of child at birth } \\
\hline & Very large & $9(18)$ & $8(21.6)$ \\
\hline & Larger than average & $8(16)$ & $7(18.9)$ \\
\hline & Average & $20(40)$ & $12(32.4)$ \\
\hline & Smaller than average & $5(10)$ & $5(13.5)$ \\
\hline & Very small & $7(14)$ & $5(13.5)$ \\
\hline & Don't know & $1(2.0)$ & $0(0)$ \\
\hline \multicolumn{4}{|c|}{ Postnatal check up } \\
\hline & No & $28(96.6)$ & 84(86.6) \\
\hline & Yes & $1(3.4)$ & 13(13.4) \\
\hline \multicolumn{4}{|l|}{ Height(Cm) } \\
\hline & Less than 150 & $10(14.3 \%)$ & 25(11.9) \\
\hline & Equal or greater than 150 & $60(85.7)$ & $185(88.1)$ \\
\hline \multicolumn{4}{|c|}{ Preceding birth interval(months) } \\
\hline & $<24$ & 15(31.3) & $25(23.6)$ \\
\hline & Equal or greater than 24 & $33(68.8)$ & $81(76.4)$ \\
\hline \multicolumn{4}{|c|}{ Ever had a terminated pregnancy } \\
\hline & No & $56(80.0)$ & 190(90.5) \\
\hline & Yes & $14(20.0)$ & $20(9.5)$ \\
\hline
\end{tabular}

Page $11 / 15$ 
Table 3: Factors associated with anemia using bivariate and multivariable logistic regression model $(n=280)$ 


\begin{tabular}{|c|c|c|c|c|c|c|c|}
\hline \multirow[t]{3}{*}{ Variables } & & \multicolumn{2}{|c|}{$\begin{array}{l}\text { Experienced Obstetric } \\
\text { Fistula }\end{array}$} & \multirow{3}{*}{$\begin{array}{l}\text { COR } \\
(95 \% \mathrm{Cl})\end{array}$} & \multirow[t]{3}{*}{$\begin{array}{l}\mathrm{p}- \\
\text { value }\end{array}$} & \multirow{3}{*}{$\begin{array}{l}\text { AOR } \\
(95 \% \mathrm{Cl})\end{array}$} & \multirow[t]{3}{*}{$\begin{array}{l}\mathrm{p}- \\
\text { value }\end{array}$} \\
\hline & & Yes & No & & & & \\
\hline & & $\mathrm{n}(\%)$ & $\mathrm{n}(\%)$ & & & & \\
\hline \multirow{2}{*}{$\begin{array}{l}\text { Age at first } \\
\text { marriage } \\
\text { (Years) }\end{array}$} & $<18$ & $62(88.6)$ & 163(77.6) & $\begin{array}{l}3.717 \\
(3.123,5.671)\end{array}$ & 0.01 & $\begin{array}{l}3.294 \\
(2.832,4.601)\end{array}$ & $0.01^{*}$ \\
\hline & $\geq 18$ & $8(11.4)$ & $47(22.4)$ & 1 & & & \\
\hline \multirow[t]{2}{*}{ Height(Cm) } & $<150$ & $10(14.3)$ & 25(11.9) & $1.982(1.321,2.211)$ & 0.039 & & \\
\hline & $>150$ & $60(85.7)$ & 185(88.1) & 1 & & & \\
\hline \multirow{5}{*}{$\begin{array}{l}\text { Wealth } \\
\text { index }\end{array}$} & Poorest & $21(30)$ & $51(24.3)$ & $4.621(2.998,6.123)$ & 0.01 & $3.34(2,238,5.015)$ & $0.01 *$ \\
\hline & Poorer & $10(14.3)$ & $26(12.4)$ & $0.871(0.745,1.017$ & 0.090 & & \\
\hline & Middle & $14(20.0)$ & $26(12.4)$ & $\begin{array}{l}1.037 \\
(0.881,1.221)\end{array}$ & 0.562 & & \\
\hline & Richer & 10(14.3) & $27(12.9)$ & $\begin{array}{l}1.124 \\
(0.889,1.421)\end{array}$ & 0.330 & & \\
\hline & Richest & $15(21.4)$ & $80(38.1)$ & 1 & & & \\
\hline \multirow[t]{2}{*}{ Residence } & Urban & 11(15.7) & $74(35.2)$ & 1 & & & \\
\hline & Rural & $59(84.3)$ & $136(64.8)$ & $6.123(4.981,8.413)$ & 0.01 & $5.141(4.262,7.521)$ & $0.01 *$ \\
\hline \multirow{2}{*}{$\begin{array}{l}\text { Has } \\
\text { television }\end{array}$} & No & 61(87.1) & $150(71.4 \%)$ & $2.323(1.721,2.986)$ & 0.04 & & \\
\hline & Yes & $9(12.9)$ & $60(28.6)$ & 1 & & & \\
\hline \multirow[t]{2}{*}{ Literacy } & Literate & $24(34.3)$ & 102(48.6) & & & & \\
\hline & Illiterate & $46(65.7)$ & $108(51.4 \%)$ & & & & \\
\hline \multirow[t]{4}{*}{$\begin{array}{l}\text { Number of } \\
\text { house hold } \\
\text { members }\end{array}$} & & & & & & & \\
\hline & 1 & $7(10.0)$ & $29(13.8)$ & 1 & & & \\
\hline & $2-4$ & $22(31.4)$ & $48(22.9)$ & $\begin{array}{l}1.258 \\
(0.890,1.395)\end{array}$ & 0.076 & & \\
\hline & $>4$ & $41(58.6 \%)$ & 133(63.3) & $2.912(1.631,3.211)$ & 0.046 & & \\
\hline \multirow{5}{*}{$\begin{array}{l}\text { Ever had a } \\
\text { terminated } \\
\text { pregnancy }\end{array}$} & No & $56(80)$ & $190(90.5 \%)$ & & & & \\
\hline & Yes & $14(20)$ & $20(9.5)$ & & & & \\
\hline & $\begin{array}{l}\text { Mainly } \\
\text { respondent }\end{array}$ & $3(4.8)$ & $12(25)$ & $\begin{array}{l}1.258 \\
(0.994,1.592)\end{array}$ & 0.057 & & \\
\hline & $\begin{array}{l}\text { Mainly } \\
\text { husband, } \\
\text { partner }\end{array}$ & $16(25)$ & $3(6.3)$ & $\begin{array}{l}1.554 \\
(1.248,1.693)\end{array}$ & 0.02 & $\begin{array}{l}1.308 \\
(1.124,1.670)\end{array}$ & $0.032^{*}$ \\
\hline & $\begin{array}{l}\text { Joint } \\
\text { decision }\end{array}$ & $44(69.3)$ & $33(68.8)$ & 1 & & & \\
\hline
\end{tabular}




\section{Figures}

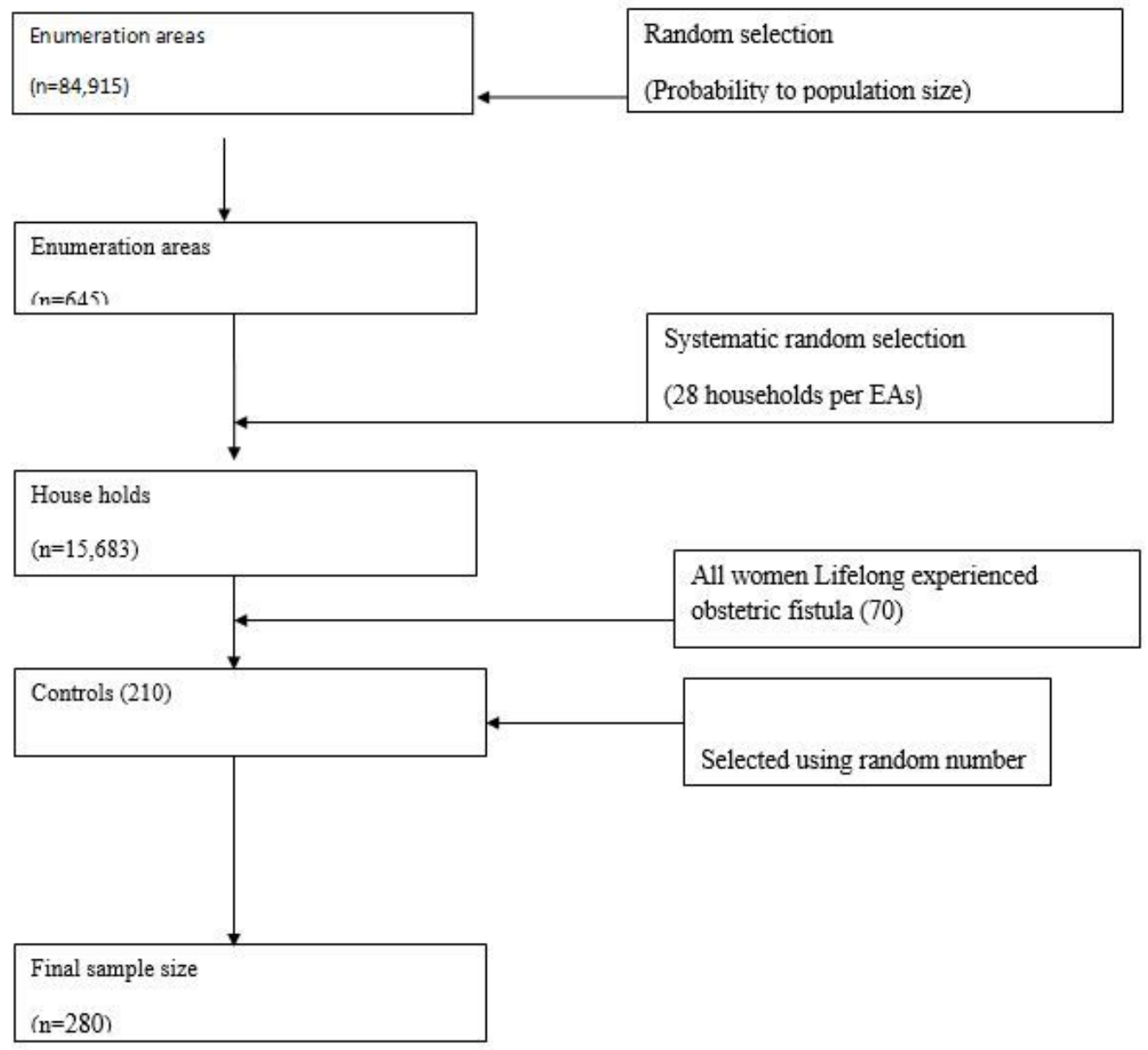

\section{Figure 1}

Flow chart of sample selection technique EDHS $2016(n=280)$. 


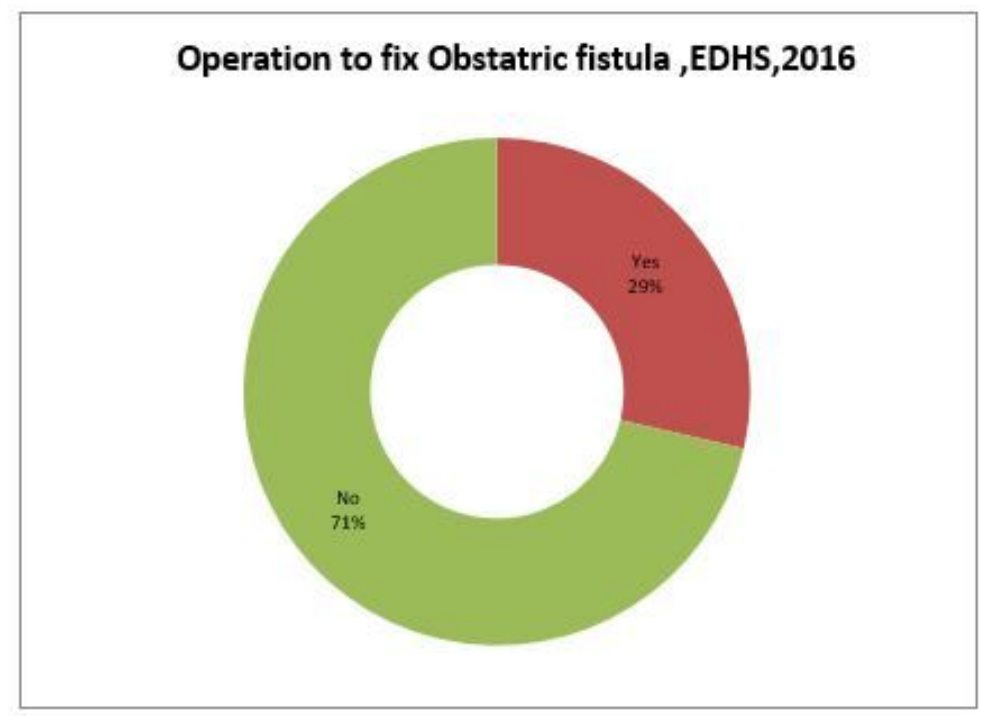

Figure 2

Number of operation to fix obstetric fistula cases, EDHS $(n=70)$ 